Faculty of Science

Faculty Publications

Ions, metabolites, and cells: Water as a reporter of surface conditions during bacterial growth

Tasha A. Jarisz, Sarah Lane, Lea Gozdzialski, and Dennis K. Hore

April 2018

This article was originally published at:

https://doi.org/10.1063/1.5023748

Citation for this paper:

Jarisz, T. A.; Lane, S.; Gozdzialski, L.; \& Hore, D. K. (2018). Ions, metabolites, and cells: Water as a reporter of surface conditions during bacterial growth. The Journal of Chemical Physics, 148, 222825. DOI: 10.1063/1.5023748 


\section{lons, metabolites, and cells: Water as a reporter of surface conditions during bacterial growth}

Cite as: J. Chem. Phys. 148, 222825 (2018); https://doi.org/10.1063/1.5023748

Submitted: 27 January 2018 . Accepted: 15 March 2018 . Published Online: 05 April 2018

Tasha A. Jarisz, Sarah Lane, Lea Gozdzialski, and Dennis K. Hore (D)

\section{COLLECTIONS}

Paper published as part of the special topic on lons in Water
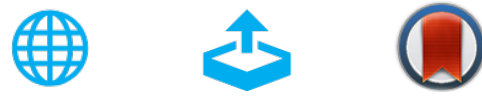

View Online

\section{ARTICLES YOU MAY BE INTERESTED IN}

Relative permittivity in the electrical double layer from nonlinear optics

The Journal of Chemical Physics 148, 222808 (2018); https://doi.org/10.1063/1.5011977

Molecular dynamics study of structure and vibrational spectra at zwitterionoic lipid/ aqueous $\mathrm{KCl}, \mathrm{NaCl}$, and $\mathrm{CaCl}_{2}$ solution interfaces

The Journal of Chemical Physics 148, 222801 (2018); https://doi.org/10.1063/1.5006543

Probing the Hofmeister series beyond water: Specific-ion effects in non-aqueous solvents

The Journal of Chemical Physics 148, 222805 (2018); https://doi.org/10.1063/1.5017278
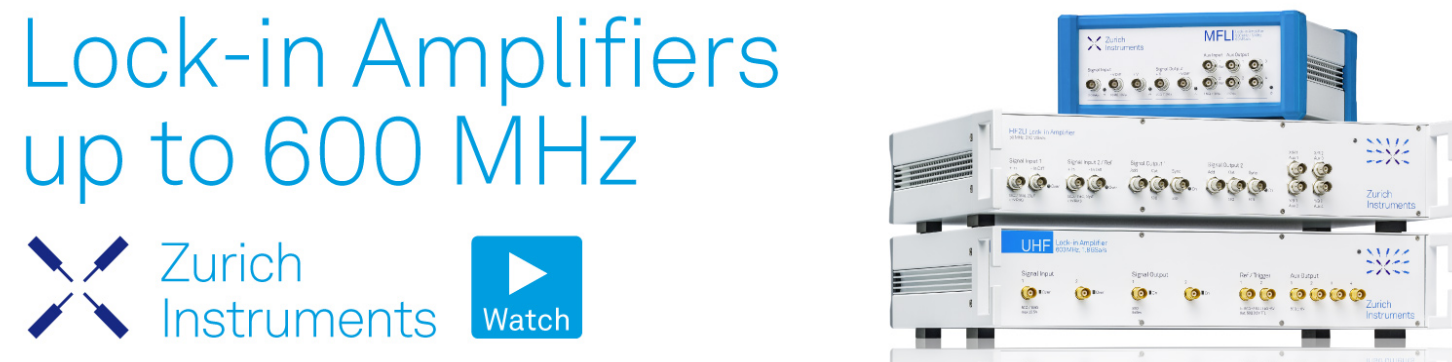


\title{
lons, metabolites, and cells: Water as a reporter of surface conditions during bacterial growth
}

\author{
Tasha A. Jarisz, Sarah Lane, Lea Gozdzialski, and Dennis K. Hore ${ }^{a)}$ \\ Department of Chemistry, University of Victoria, Victoria, British Columbia V8W 3V6, Canada
}

(Received 27 January 2018; accepted 15 March 2018; published online 5 April 2018)

\begin{abstract}
Surface-specific nonlinear vibrational spectroscopy, combined with bulk solution measurements and imaging, is used to study the surface conditions during the growth of E. coli. As a result of the silica high surface charge density, the water structure at the silica-aqueous interface is known to be especially sensitive to $\mathrm{pH}$ and ionic strength, and surface concentration profiles develop that can be appreciably different from the bulk solution conditions. We illustrate that, in the presence of growing cells, a unique surface micro-environment is established as a result of metabolites accumulating on the silica surface. Even in the subsequent absence of the cells, this surface layer works to reduce the interfacial ionic strength as revealed by the enhanced signal from surface water molecules. In the presence of growing cells, an additional boost in surface water signal is attributed to a local $\mathrm{pH}$ that is higher than that of the bulk solution. Published by AIP Publishing. https://doi.org/10.1063/1.5023748
\end{abstract}

\section{INTRODUCTION}

The manner in which biomolecules interact with surfaces plays a key role in a host of applications ranging from implant biocompatibility and biosensors to drug delivery platforms and chromatography. ${ }^{1}$ Protein and cell adhesion is a complex phenomenon, governed by interactions between molecules on the cell surface, together with the nature of the substrate and surrounding solution environment. ${ }^{2}$ When a surface is placed in contact with a proteinaceous solution, rapid adsorption causes the formation of a conditioning film, which is necessary for subsequent adhesion of cells-an important step in the formation of biofilms. ${ }^{3-6}$ Biofilms have significant consequences for industry and public health, due to their central role in equipment fouling and infectious diseases. ${ }^{7,8}$ In the initial stages of bacterial colony formation, cells irreversibly adhere to the surface and begin production of extracellular polymeric substances (EPSs) which, over a period of hours to days, completely envelop the surface. ${ }^{9}$ Secretion of EPS is one of their unique features, improving adhesion and cohesion and offering enhanced resistance to environmental stresses. ${ }^{10-12}$ Cells within this polymeric extracellular matrix are distinct from their planktonic counterparts and grow and respond to changes in their immediate environment. ${ }^{13}$ The composition of the EPS is dependent on the stage of growth and other critical features of the environment which dictate the formation and proliferation rate of the eventual biofilm. ${ }^{14}$ In addition, the EPS secreted by bacteria readily bind cations, anions, proteins, and other organic molecules near the cells. ${ }^{14}$ Studies varying the surface and solution conditions have concluded that the nature of the surface, including its charge, hydrophobicity, and roughness, and $\mathrm{pH}$ and ionic strength of the environment are critical features influencing the amount and conformation of adsorbed

a)Author to whom correspondence should be addressed: dkhore@uvic.ca proteins and cells. ${ }^{15-20}$ The solvation environment plays an integral role in both protein and bacterial adsorption such that changes in the hydration structure at the surface are a sensitive measure of early adhesion events. Water constitutes by far the largest part of the environment in which most bacteria grow and is also the major component of the EPS matrix. Polymers within this matrix trap ions and water molecules, creating chemical gradients that are distinct from the bulk solution. ${ }^{14}$ The creation of these micro-environments, in which water plays a significant role, is important for bacterial adhesion and colony growth. Water molecules may compete for hydrogen bonding opportunities with both the protein and surface, thereby suppressing protein adsorption. ${ }^{21,22}$ On the other hand, dehydration of hydrophobic regions on the protein or substrate is thermodynamically favourable due to the increased entropy of the displaced waters. This serves to promote protein adsorption, especially for globular proteins that may alter their conformation and unfold upon adhesion to a surface. ${ }^{23}$ The surface charge and presence of co-solvating ions have also been shown to be important factors in mediating protein adsorption. ${ }^{24}$ Consequently, the extent of protein adhesion is influenced by the $\mathrm{pH}$ and ionic strength of the aqueous medium.

Silica is an ideal surface to study bacterial adhesion due to its prevalence in many biological applications, including chromatography, sensors, assays, implants, and metal-ion extraction. ${ }^{25}$ Moreover, its high surface charge density makes it very sensitive to small changes in $\mathrm{pH}$, especially in the 6-8 range of biological systems. ${ }^{26}$ As the $\mathrm{pH}$ of the solution is increased, deprotonation of silanol groups to form siloxide results in a more negatively charged surface. Consequently, the structure of water molecules at the silicaaqueous interface is affected by alterations in $\mathrm{pH}$, as the degree to which interfacial molecules are ordered depends on the extent of hydrogen bonding and the surface charge. ${ }^{27-29}$ Ions in solution are also known to significantly alter the 
water structure at silica surfaces. ${ }^{28,30-37}$ Studies have shown that increasing the ionic strength of the solution results in a decreased ordering of water molecules at the interface. This may occur via two different mechanisms: increased screening of the partially negative surface charge on silica and compression of the electrical double layer and/or electrostatic interaction of hydrated cations at the negatively charged surface, thereby disrupting hydrogen bonding between water molecules. ${ }^{30}$

It is increasingly recognized that early protein conditioning and cell-surface interactions are prerequisites to the attachment of bacteria and formation of biofilms. Although scientists have amassed considerable knowledge of the growth, composition, and structure of mature biofilms, ${ }^{38-40}$ the details of such a conditioning layer and early bacterial adsorption are not clear. ${ }^{4,12,41-44}$ The role of the interfacial environment, including water structure, $\mathrm{pH}$, and ionic strength, on initial bacterial adsorption and early development of colonies are acknowledged as critical factors, yet remain largely unknown. ${ }^{45-47}$ This is partly owing to the complexity of the interfacial environment (surface roughness, charge, hydrophobicity; solution ionic strength, $\mathrm{pH}$, composition of osmolytes) and partly a result of the paucity of in situ, label-free techniques that can probe the interfacial environment with sufficient selectivity and structural sensitivity. The physical and chemical nature of the substrate, and hence conditioned surface, including the structure of interfacial water molecules and the role of ions, are key aspects that need to be better understood. ${ }^{48,49}$ Thus, a more sensitive and surface specific technique, capable of in situ characterization of the solid-aqueous interface, is needed. Among the probes available for surface analysis, visible-infrared sumfrequency generation (SFG) spectroscopy is unique in its ability to provide quantitative molecular level information at buried interfaces with extreme surface-specificity. ${ }^{50-53}$ This is a result of the second-order nonlinear susceptibility tensor $\chi^{(2)}$ vanishing in centrosymmetric materials, such as the bulk solution phase. Therefore, this second-order nonlinear vibrational technique is ideal for monitoring alterations in the surface-bound water structure, in order to serve as a predictor for interfacial environmental conditions that lead to adhesion.

Here, we use SFG spectroscopy, in combination with imaging and solution characterization techniques, to monitor how early protein conditioning and E. coli cell adhesion influence the interfacial environment at silica surfaces. We illustrate that SFG spectroscopy is a sensitive probe of the local ionic strength, which is reduced as a result of ion adsorption by EPS of the bacterial matrix, and local $\mathrm{pH}$, which is increased as a result of metabolic activities of bacteria at the surface.

\section{EXPERIMENTAL}

\section{A. Cell culture}

Escherichia coli K12 MG1655 (ATCC 700926) were stored at $-80{ }^{\circ} \mathrm{C}$ in Lysogeny broth (LB, Difco Laboratories) containing 50\% (vol./vol.) glycerol. Working liquid cultures were inoculated from LB agar plates into $500 \mathrm{ml}$ of LB and aerated with vigorous stirring at $37^{\circ} \mathrm{C}$ for $25 \mathrm{~h}$. Our Lennox formulation of $\mathrm{LB}$ consists of tryptone $(10 \mathrm{~g} / \mathrm{l})$, yeast extract $(5 \mathrm{~g} / \mathrm{l})$, and sodium chloride $(5 \mathrm{~g} / \mathrm{l})$. Offline growth was monitored by measuring the optical density at $600 \mathrm{~nm}$ using an Ultrospec 10 Cell Density Meter (Amersham Biosciences). In the case of online growth, $8 \mathrm{ml}$ of the offline culture was placed into the sample chamber of the SFG spectrometer $2 \mathrm{~h}$ after inoculation (while in the lag phase). The bacteria were grown inside this Teflon chamber at $37{ }^{\circ} \mathrm{C}$ and were aerated with stirring.

\section{B. SFG measurements}

SFG measurements were performed using a picosecond laser system (Ekspla PL2241) ${ }^{54}$ The frequency-doubled $532 \mathrm{~nm}$ visible beam was s-polarized and defocused to a diameter of $1 \mathrm{~mm}$ at the surface of an IR-grade fused silica dove prism (Del Mar Photonics), approaching the surface at $68^{\circ}$ with an energy of $100 \mu \mathrm{J} /$ pulse at a repetition rate of $10 \mathrm{~Hz}$. Mid-infrared pulses from 2800 to $3550 \mathrm{~cm}^{-1}$ were generated in $\mathrm{AgGaS}_{2}$ in a wavelength-scanning optical parametric generator (Ekspla PG501). The p-polarized IR beam was nominally $200 \mu \mathrm{J} /$ pulse and was incident at $60^{\circ}$ with a diameter of $0.5 \mathrm{~mm}$. The sample cell consisted of a custom Teflon vessel mounted against the fused silica prism with a fluoropolymer O-ring (Marco Rubber, $\mathrm{NH}$ ) and maintained at $37^{\circ} \mathrm{C}$ by means of a recirculating water bath channeled through an aluminum block enclosing the Teflon. The s-polarized component of the SFG intensity was collected, and the average of 200 laser shots were acquired at each IR wavenumber.

\section{Cell solution characterization}

Fractions of the working E. coli culture were collected at various times during the lag, exponential, and stationary phases and stored at $4{ }^{\circ} \mathrm{C}$ overnight. The fractions were then centrifuged (Eppendorf 5810R) at $2250 \mathrm{rcf}$ for $45 \mathrm{~min}$ at $4{ }^{\circ} \mathrm{C}$. The supernatant was poured off immediately and then filtered using a sterile $0.2 \mu \mathrm{m}$ filter and $5 \mathrm{cc}$ syringe. The $\mathrm{pH}$ of each fraction was measured using a $\mathrm{pH}$ meter (VWR Symphony SB70P) and glass electrode (VWR 4002-850) using a twopoint calibration method with $\mathrm{pH} 4$ and $\mathrm{pH} 10$ buffers. The conductivity of each fraction was measured with a traceable conductivity meter (VWR) after calibration with a standard potassium chloride solution prepared as follows: $\mathrm{KCl}$ ( $\mathrm{ACP}$ Chemicals) was oven-dried at $110{ }^{\circ} \mathrm{C}$ for $5 \mathrm{~h}$ and dissolved in $18.2 \mathrm{M} \Omega \mathrm{cm}$ water to make a $0.01 \mathrm{M}$ solution. The temperature-corrected conductivity reading was adjusted to $1323 \mu \mathrm{S} / \mathrm{cm}$ at $22{ }^{\circ} \mathrm{C}$.

\section{Quartz crystal microbalance}

Quartz crystal microbalance with dissipation monitoring (QCM-D, Q-Sense, Gothenburg, Sweden) experiments were performed at $37{ }^{\circ} \mathrm{C}$ on $\mathrm{SiO}_{2}$ coated sensors. Prior to use, the sensors were rinsed with $18.2 \mathrm{M} \Omega \mathrm{cm}$ water, dried under nitrogen, and then put in an UV-ozone cleaner (Bioforce Nanosciences) for $10 \mathrm{~min}$. Frequency and dissipation shift data were collected upon flowing water at $0.1 \mathrm{ml} / \mathrm{min}$, followed by the LB solution until equilibrium was reached 
(approximately $30 \mathrm{~min}$ ). These data were analyzed using a Kevin-Voigt model ${ }^{55,56}$ to determine the adsorbed mass and rheological properties of the surface. ${ }^{57}$

\section{E. Imaging}

Following some of the experiments, the solution was drained from the sample cell, and the silica prism was detached and rinsed with distilled water. To improve our statistics, we also performed additional growth measurements independent of the SFG experiments for the purpose of image analysis. Crystal violet was applied, allowed to maintain contact for $60 \mathrm{~s}$, and then rinsed with distilled water. The prism surface was then imaged at $1000 \times$ using a $100 \times$ oil-immersion objective on an inverted microscope (Nikon Diaphot-TMD). This enabled high magnification without the use of long working distance objectives as the dove prism had a thickness of $10 \mathrm{~mm}$. Image analysis was performed using the code we developed in Python using the SciPy numerical libraries ${ }^{58}$ and the Matplotlib 2D graphics library. ${ }^{59}$ This consisted of an initial flatting step where a single-channel image was created from the average of each of the RGB channels on a $(0,255)$ scale and then renormalized to $(0,1)$. A subsequent binary image was obtained in a subsequent flattening step where pixels were assigned a value of 0 if they were below a cutoff value and a value of 1 otherwise. This cutoff was determined from the contrast between regions with obvious lack of colonies and those with large colonies and had typical values between 0.7 and 0.8. This data set was then used for colony counting and size distribution reporting. The final binary image was inverted so that colonies appeared dark (black) and unadhered regions were white.

\section{RESULTS}

\section{A. SFG response to online vs offline growth conditions}

The population of E. coli was monitored by measuring the optical density at $600 \mathrm{~nm}$. As shown in Fig. 1(a) (points), this followed a logarithmic behavior, enabling the data to be fit by

$$
f(t)=\frac{A}{1+e^{-k\left(t-t_{m}\right)}}+b,
$$

where $A$ is the amplitude, $k$ is the growth rate, $t_{m}$ is the midpoint of the exponential phase, and $b$ is any offset. Fitting the data to this equation resulted in $k=0.87 \mathrm{~h}^{-1}$ and $t_{m}=8.1 \mathrm{~h}$, as indicated by the line in Fig. 1(a). Based on this data, we consider the lag phase to exist up to $4 \mathrm{~h}$, the exponential phase to exist from 4 to $15 \mathrm{~h}$, and the stationary phase to exist after $15 \mathrm{~h}$. We refer to this as the offline growth, as no vibrational spectra were recorded during this period.

We then perform the same experiment, but inside the thermostated sample chamber of our SFG spectrometer, referred to as online growth. The intensity of the SFG signal is proportional to the square of the sum of second- and third-order contributions to the polarization. In our polarization scheme, we probe only a single element of $\chi^{(2)}$ and $\chi^{(3)}$,
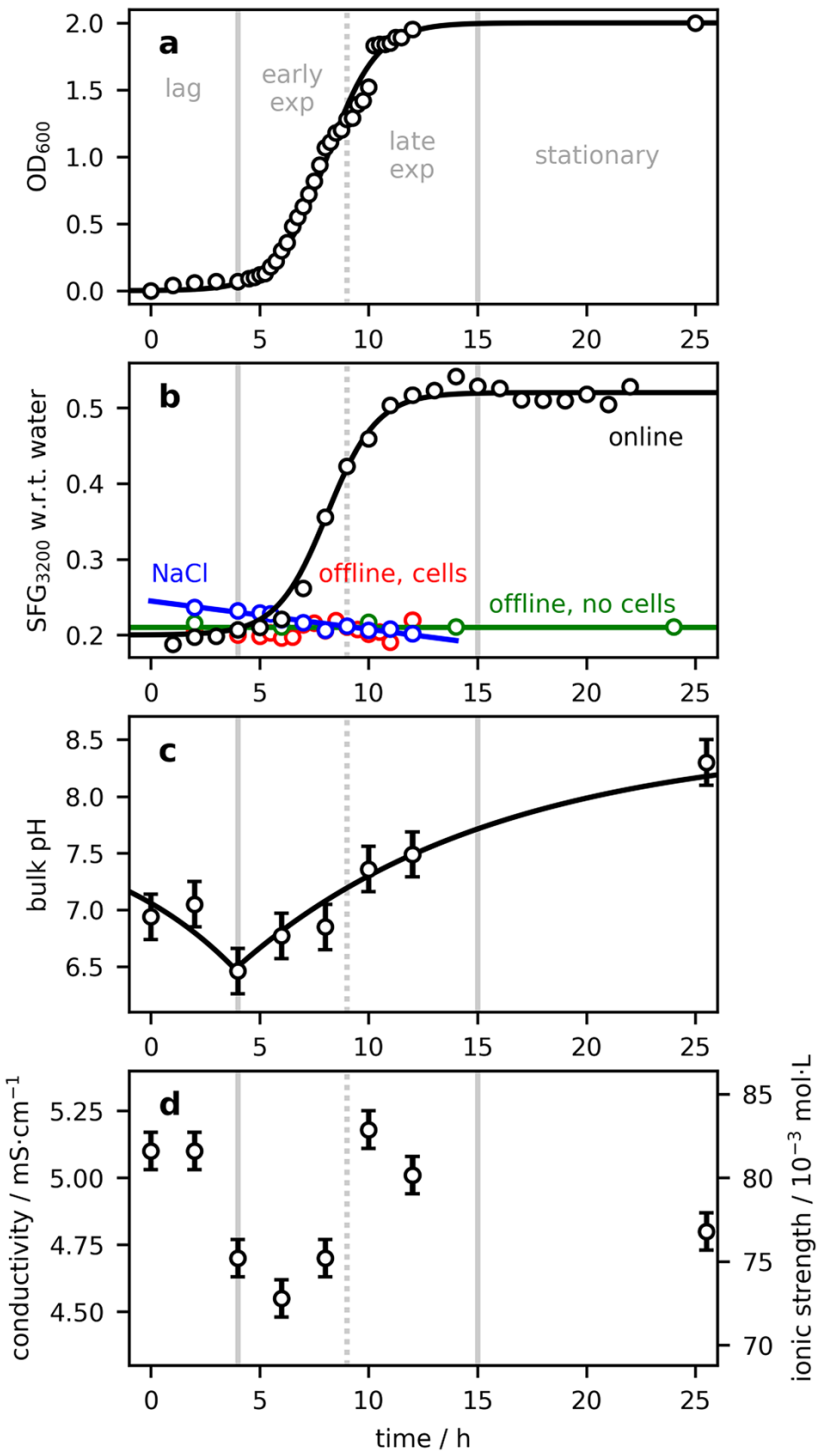

FIG. 1. (a) E. coli K12 growth curve as determined from the optical density at $600 \mathrm{~nm}$ (points) and fit to the model in Eq. (1) (line); (b) online growth SFG intensity (black points) at $3200 \mathrm{~cm}^{-1}$ with respect to the neat water-silica interface, superimposed on the same growth model (black line); signal from cells grown offline (red) followed by centrifuged fractions (green); $0.08 \mathrm{M}$ $\mathrm{NaCl}$ rinse (blue); (c) bulk solution $\mathrm{pH}$; (d) bulk solution conductivity.

$$
\begin{aligned}
I & \propto\left|P^{(2)}+P^{(3)}\right|^{2} \\
& =\left|L_{y} L_{y} L_{z} \chi_{y y z}^{(2)} E_{\mathrm{vis}} E_{\mathrm{IR}}+L_{y} L_{y} L_{z} \int_{0}^{\infty} \chi_{y y z z}^{(3)} E_{\mathrm{vis}} E_{\mathrm{IR}} E_{0}(z) d z\right|^{2},
\end{aligned}
$$

where $E_{\mathrm{vis}}$ and $E_{\mathrm{IR}}$ are the electric components of the fields from the laser approaching the sample and $E_{0}(z)$ is the distance-dependent static field originating at the silica surface. The integration in Eq. (2) results in an interference between the $\chi^{(2)}$ and $\chi^{(3)}$ terms that is modulated by the ionic strength and wavevector mismatch. ${ }^{60,61}$ The local field correction factors $L$ provide the laser fields at the silica-aqueous interface and are calculated according to the refractive index and beam angles. ${ }^{62}$ As we will describe later, these factors are especially important when near the critical angles, as small changes in the refractive index can have a marked effect on the SFG signal. 


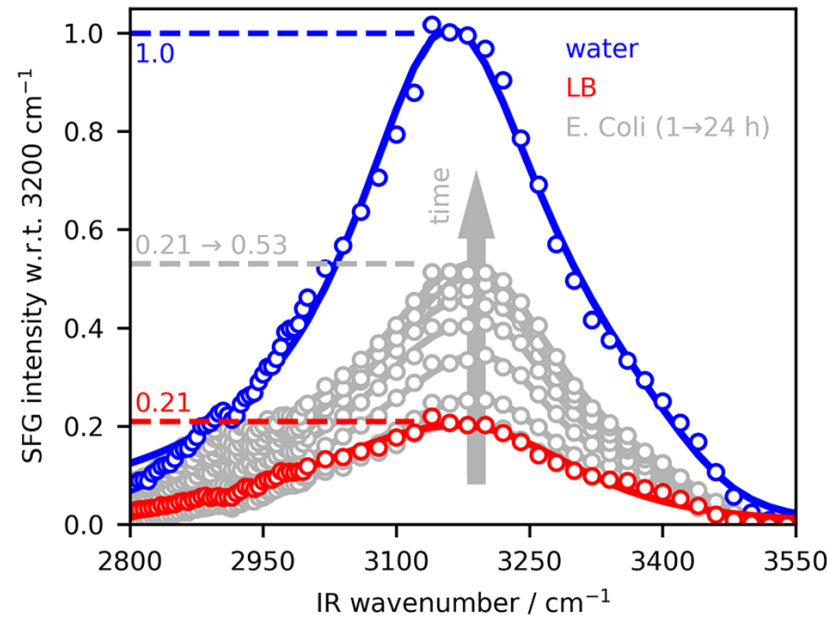

FIG. 2. SFG spectra collected at the aqueous-silica interface for water (blue), LB growth medium (red), and E. coli K12 (gray). During bacterial growth, SFG intensity increases from $21 \%$ of the initial silica-water signal to $53 \%$ of this level. The intensity at $3200 \mathrm{~cm}^{-1}$ is plotted in Fig. 1(b) (black points).

As shown in Fig. 2, we first collect the signal of water adjacent to silica from 2800 to $3550 \mathrm{~cm}^{-1}$ (blue trace), corresponding to the $\mathrm{O}-\mathrm{H}$ stretching vibration. We then remove the water and fill the chamber with fresh LB growth medium. The resulting spectrum (red trace) shows essentially the same shape, but with only $21 \%$ of the intensity. For all subsequent SFG data, we will display the intensity relative to that of water at $3200 \mathrm{~cm}^{-1}$. When the LB is now replaced with growth media that is inoculated with cells, spectra obtained (gray traces) for the first few hours have the same shape and intensity as the initial LB spectrum. After some time, however, the spectra increase and then reach a plateau. The trends in this data are more clearly observed in Fig. 1(b), as the points display a logarithmic growth. The line is a plot of Eq. (1), with the same values of $k$ and $t_{m}$, as was obtained for the $\mathrm{OD}_{600}$ data. Here only $A$ and $b$ have been adjusted to match the scale of the SFG data, normalized with respect to the water signal. It is curious that the signal increases to such a large extent (more than $250 \%$ ) and that the trend so closely matches the population growth curve. In order to further investigate the origins of this effect, we perform a separate experiment in which fractions of the population (as monitored in an $\mathrm{OD}_{600}$ measurement) are isolated, centrifuged, and filtered to remove the cells and then introduced to the SFG spectrometer. We have selected one snapshot from the lag phase, one from the early exponential phase and two from the late exponential phase, and one from the stationary phase. As shown in Fig. 1(b) (green points), all fractions have the same SFG response throughout the lag, exponential, and stationary phases, with no increase observed. As it would appear that the dramatic difference between these two data sets may be the result of the cells being present, a final experiment studied the collected fractions without separating the cells and introduced them into the SFG spectrometer. The data [red points in Fig. 1(b)] show only small changes in SFG signal intensity throughout each phase of growth, indicating that there is little difference between the presence and absence of cells in the offline SFG data.

We then investigate whether the increase in signal for online growth is due to the change in composition of the surface or bulk environments or whether it has its own time dependence. We return to the centrifuged fractions and introduce them in succession onto clean silica surfaces. Before the introduction of the solution, the water signal is measured as a reference, and the surface is then pre-conditioned with LB. We have confirmed that the LB signal does not change with time, even over a $24 \mathrm{~h}$ period [Fig. 3(b)]. The signal obtained from each fraction is then monitored for $4 \mathrm{~h}$, as shown in Fig. 3(a). Consistent with the data shown in Fig. 1(b) (green points), the SFG signal corresponding to the initial exposure to the solutions is fairly constant at $21 \%$ of the water value. Here it is noted that, as in the case of LB, there is also no change over time throughout the lag and exponential phases. However, the late exponential $14 \mathrm{~h}$ fraction $\left(\mathrm{OD}_{600}=1.76\right)$ exhibits a more than $50 \%$ increase in signal over the $4 \mathrm{~h}$ monitoring period. Further into the stationary phase, the signal also increases with time, but to a lesser extent. It can also be seen in Fig. 3(a) that the $25 \mathrm{~h}$ fractions grown both online and offline show identical increases over the $4 \mathrm{~h}$ period, reaching a plateau at the same time and intensity.

\section{B. Solution conditions during cell growth}

The bulk $\mathrm{pH}$ and conductivity of the LB fractions after supporting varying amounts of $E$. coli growth were measured, as shown in Figs. 1(c) and 1(d), respectively. Starting from a
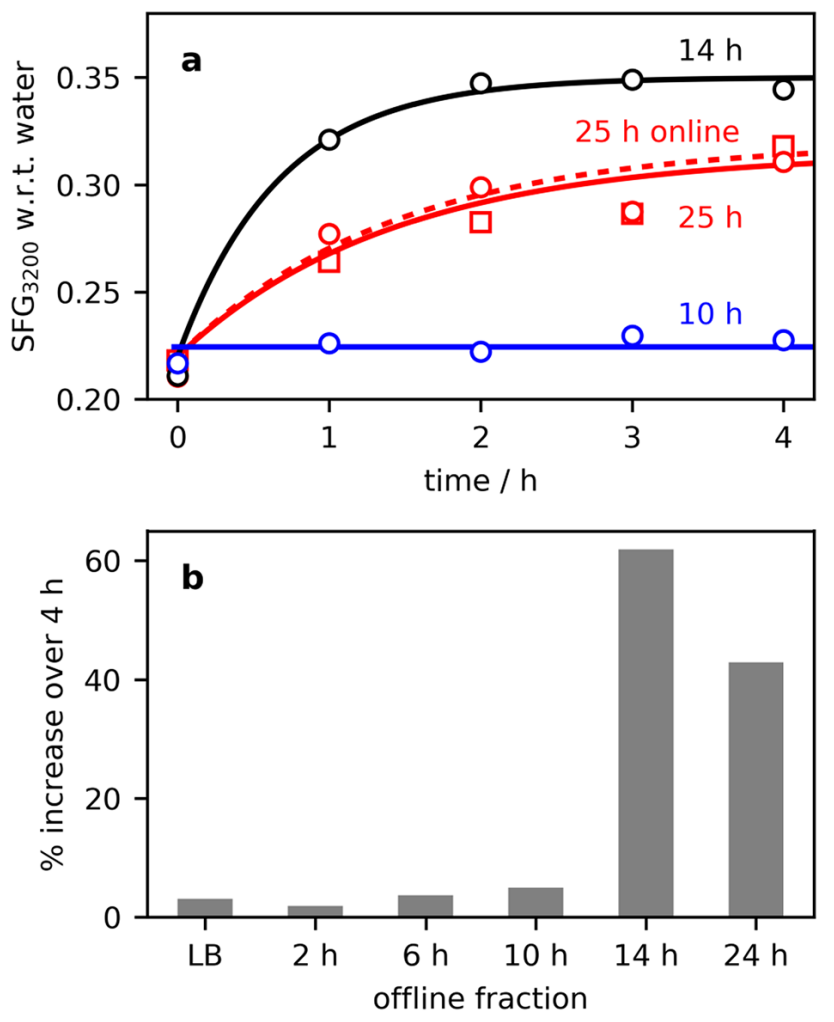

FIG. 3. (a) Evolution of the SFG signal at $3200 \mathrm{~cm}^{-1}$, normalized with respect to the water-silica interface, for different centrifuged fractions collected during offline cell growth (circles). This displayed a constant signal level over $4 \mathrm{~h}$ for all fractions up to $10 \mathrm{~h}$, followed by an exponential rise in SFG with time (solid lines) for the $14 \mathrm{~h}$ and $25 \mathrm{~h}$ fractions. For comparison, a $25 \mathrm{~h}$ fraction from online growth (squares, cells removed) was monitored and displayed the same exponential increase (dashed line). (b) The relative increase for the initial LB medium and all offline fractions. 
neutral $\mathrm{pH}$ of 7.0, the $\mathrm{pH}$ decreases to 6.5 by the end of the lag phase and then abruptly increases during the exponential phase, reaching a plateau at $\mathrm{pH} 8.2$ in the stationary phase. The conductivity $\gamma$, however, remained relatively constant throughout the $E$. coli growth phases, with the ionic strength varying by only $10 \%$. As the major ions in the initial $\mathrm{LB}$ are $\mathrm{Na}^{+}$and $\mathrm{Cl}^{-}$, we can estimate the ionic strength $I$ assuming a 1:1 electrolyte from the linearized relationship ${ }^{63,64}$

$$
I=a \gamma,
$$

where $a=16 \times 10^{-3} \mathrm{~mol} \mathrm{~cm} \mathrm{mS}^{-1} \mathrm{l}^{-1}, I$ is in $\mathrm{mol}^{-1}$, and $\gamma$ is in $\mathrm{mS} \mathrm{cm}^{-1}$. The results of this ionic strength estimation using Eq. (3) are shown on the right axis of Fig. 1(d).

\section{Adhered cells and surface conditions during cell growth}

Two representative images acquired after $24 \mathrm{~h}$ at $37^{\circ} \mathrm{C}$ followed by rinsing and crystal violet staining are shown in Figs. 4(a) and 4(b). The RGB color maps were flattened to create gray scale images which were then further flattened to binary images [Figs. 4(c) and 4(d)] using an automatically generated threshold value. This enabled counting of colonies and measuring their size distribution [Figs. 4(e) and 4(f)]. We have determined that the average colony surface area was less
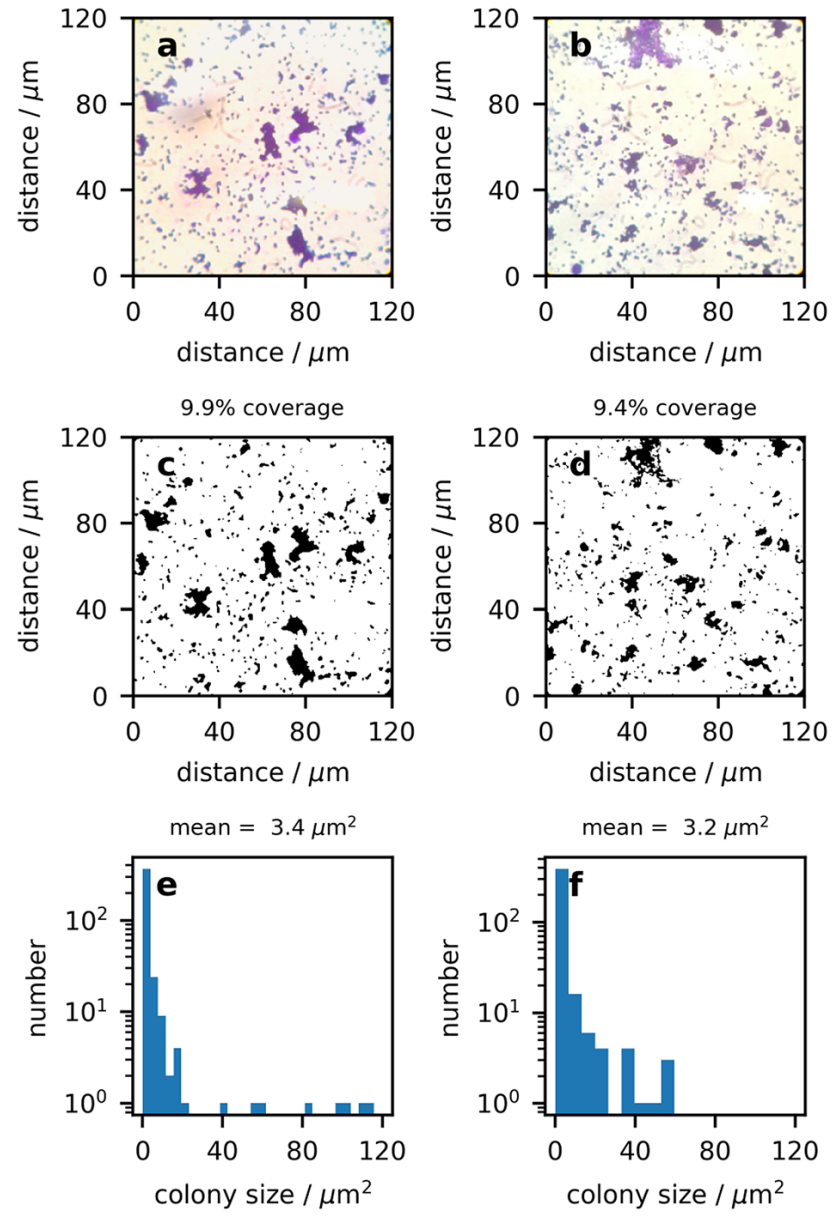

FIG. 4. [(a) and (b)] Representative images of silica surfaces following exposure to E. coli $\mathrm{K} 12$ for $24 \mathrm{~h}$ at $37^{\circ} \mathrm{C}$ following rinsing and staining with crystal violet. After thresholding, a binary map was created for the purpose of [(c) and (d)] area calculation and [(e) and (f)] colony counting. than $5 \mu \mathrm{m}^{2}$, and the surface coverage was between $5 \%$ and $15 \%$. We note that in our SFG experiment the IR beam limits the probed area and was focused to a diameter of approximately $500 \mu \mathrm{m}$, large on the scale of the heterogeneity of the adhered cell colonies. This accounts for the consistency in the trends observed for repeat SFG data. The experiments performed are probing relatively homogeneously colonized silica surfaces and the collected data reflect what is occurring when these colonies are present.

We are also interested in understanding the surface environment in the absence of cells through pre-conditioning with LB and exposure to the growth medium over time. Although there are many techniques that are capable of characterizing the roughness (profilometry, atomic force microscopy), adsorbed layer thickness (ellipsometry, QCM-D, surface plasmon resonance, dual waveguide interferometry), and composition (secondary ion mass spectrometry, energy-dispersion $\mathrm{X}$-ray spectroscopy), it is important for us to know that we are reporting on the same spot that the visible and infrared lasers are spatially overlapped during the SFG measurement. Our QCM-D measurements indicate that, when exposed to fresh LB, the adsorbed mass reaches $85 \mathrm{ng} / \mathrm{cm}^{2}$. Note that this value is determined post-rinsing and that the dynamic mass is likely even greater. We are therefore interested in an in situ probe that can be performed simultaneously with the SFG measurements. Using the offline fractions with cells removed, we rinse the solution cell with water three times after each fraction is measured, then replace the water with $0.08 \mathrm{M} \mathrm{NaCl}$ solution (to match the ionic strength of the growth medium), and monitor the SFG signal at $3200 \mathrm{~cm}^{-1}$. This is plotted with respect to the initial (clean silica surface) water signal in Fig. 1(b) (blue). We observe very little change throughout the growth period. This confirms that the increase in intensity observed during cell growth is not a result of molecules from the bulk being continually deposited on the surface since the constant composition of the $\mathrm{NaCl}$ solution allows us to discriminate between surface and bulk effects. The slight negative slope of the $\mathrm{NaCl}$ rinse data indicates that the surface waters are becoming progressively less ordered.

\section{DISCUSSION}

\section{A. The effect of bulk solution conditions on the interfacial water structure}

The influence of the nature of surfaces and interfacial environments on the water structure is a complex phenomenon, especially in biologically active systems. How bacteria and other microorganisms affect and interact with the surface is poorly understood. Here we report on changes in the interfacial water structure in the presence of growing E. coli at a silica-aqueous interface. From previous studies of this surface, it is known that the water signal increases with increasing $\mathrm{pH}$, as the surface becomes more negatively charged, and decreasing ionic strength, which reduces screening and expands the electrical double layer. ${ }^{29,36,54,65-67}$ These same trends were observed in our SFG data (Fig. 1), but subsequent exploration of the bulk environment did not explain the extent of the signal increase. 
Acidification and alkalinisation of the bulk solution were not sufficient in magnitude to explain the increase in water $\mathrm{O}-\mathrm{H}$ stretching signal observed. Darlington et al. recently reported SFG intensity as a function of $\mathrm{pH}$ at the silica-aqueous interface with $100 \mathrm{mM} \mathrm{NaCl} .{ }^{29}$ They observe the SFG water signal at $3200 \mathrm{~cm}^{-1}$ to increase approximately 1.5 times from pH 6 to 8, whereas in the online growth experiment presented here, the signal intensity increases to more than 2.5 times the initial value [Fig. 1(b)]. Thus, changes in the bulk pH alone cannot fully account for the increase in SFG intensity observed during E. coli growth.

Ionic strength effects on the silica-water interface are typically observed over many orders of magnitude. In our online growth experiments, the signal increases by $250 \%$ from the lag to stationary phase. When varying only the $\mathrm{NaCl}$ concentration, such an increase accompanies a thousand-fold reduction in ionic strength. ${ }^{66}$ The data in Fig. 1(d) show that the conductivity changes by only $10 \%$, as expected due to the high baseline ionic strength of the selected LB growth medium. We note that it has been established that the SFG signal does not change much with ionic strength in this region, making a $5 \mathrm{~g} / \mathrm{l}$ $\mathrm{NaCl}$ growth medium ideal for this study. ${ }^{66}$ Thus, changes in bulk ionic strength can only account for a small fraction of the increase in SFG intensity observed.

As we are working so close to the critical angle of the visible and SFG beams, we must concern ourselves with the so-called optical (refractive index) effects as a possible cause for the variation in SFG signal. These effects manifest themselves in the $L$ factors appearing in Eq. (2). As the product of the three local field corrections (for the SFG, visible, and infrared beams) is common to the second- and third-order terms in Eq. (2), we note that the intensity is proportional to $\left|L_{y} L_{y} L_{z}\right|^{2}$. Frequency and concentration dependent refractive data for $\mathrm{NaCl}$ solutions in the visible and midinfrared $^{68-70}$ show that the real part of the refractive index increases with increasing salt concentration [Fig. 5(a)] and the imaginary part of the refractive index decreases with increasing salt concentration [Fig. 5(b)]. This has the combined effect of substantially reducing the SFG signal through the local field factors, particularly at low ionic strength as shown in Fig. 5(c). Note that this is the opposite trend from what is observed here. If we now consider biomolecules in solution, this would increase the bulk refractive index by approximately 0.19 for each $\mathrm{g} / \mathrm{ml}$ in the bulk solution. ${ }^{71}$ At the surface, the refractive index due to adsorbed molecules depends on their coverage and degree of hydration, ${ }^{72}$ but is also higher than that of the non-adsorbed surface. We conclude that none of our observations can be explained by optical effects.

\section{B. Surface micro-environment during cell growth}

Since the increase in SFG signal so closely matches the growth curve, the biological component of our system must be considered. It is well known that during aerobic growth, E. coli consume sugars and amino acids to produce a variety of metabolites. In LB broth, the sugar content is low and instead consists predominantly of amino acids and small peptides. ${ }^{73}$ During growth, preference is given to catabolizing sugars,
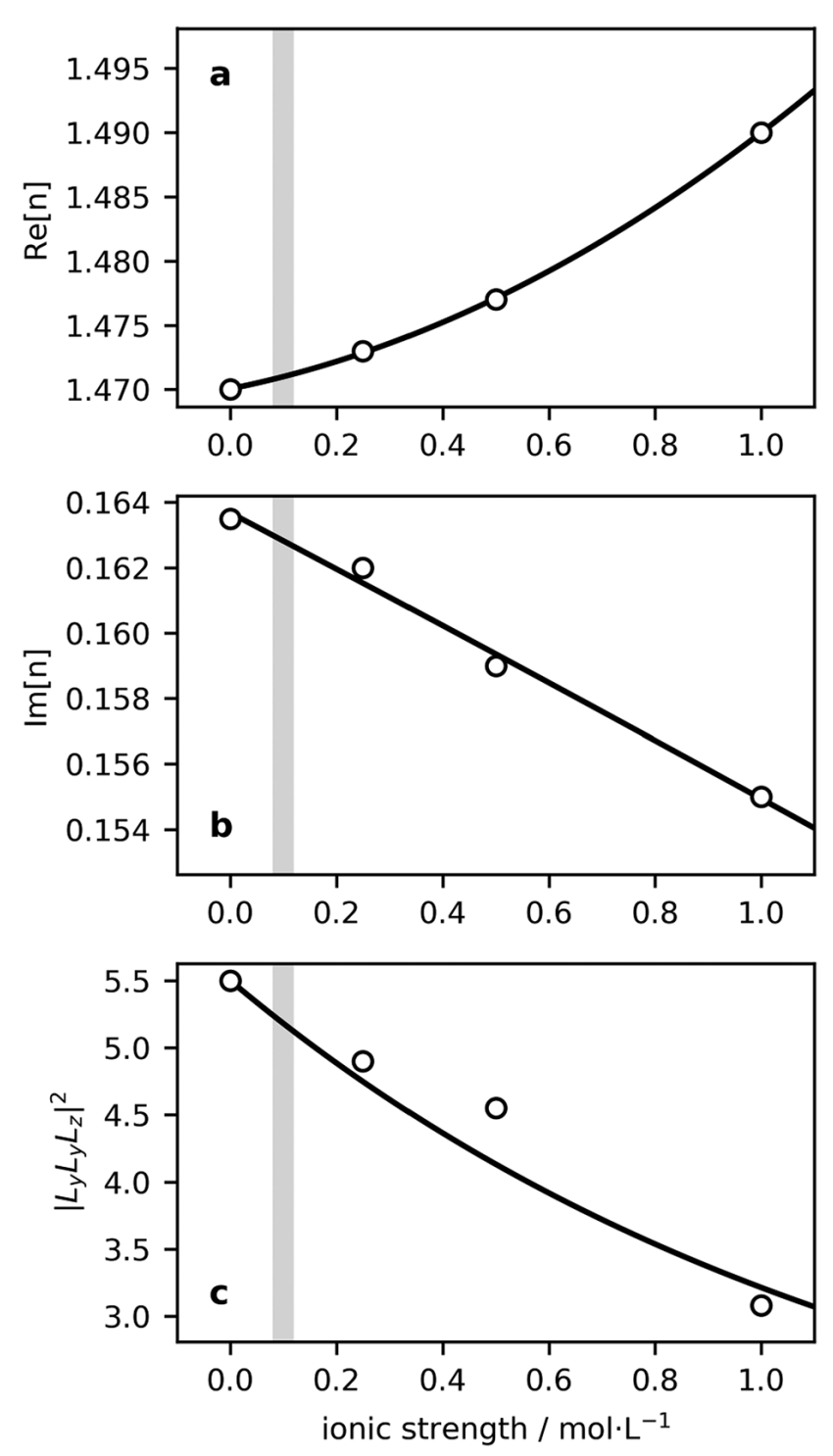

FIG. 5. Literature values of the (a) real and (b) imaginary components of the refractive index of salt water at $3200 \mathrm{~cm}^{-1}$ as a function of ionic strength. (c) The effect of these optical constants on the local field correction factors. The shaded region highlights the behavior for ionic strengths in the vicinity of $100 \mathrm{mM}$.

which results in the production of carbonic acid during respiration. ${ }^{74}$ This, in combination with exposure to atmospheric carbon dioxide, causes acidification of the surrounding environment and is observed as the initial decrease in $\mathrm{pH}$ during the lag phase [Fig. 1(c)]. If sugars or other carbohydrates are not present in sufficient quantity, metabolism switches to the use of amino acids, followed by peptides, both of which result in the production of ammonium and increase the $\mathrm{pH}$ of the environment. This, too, can be seen over the course of exponential to early stationary phases in our results.

As bacteria interact with surfaces or other cells, they become altered and begin to form colonies at the surface, eventually producing a complex network of extracellular polymeric substances (EPSs) that are characteristic of mature biofilms. ${ }^{13}$ A key factor in this process is the presence of a conditioning film which forms on the surface from deposition of proteins or cell debris from the surrounding environment and whose purpose is to regulate cellular adherence. ${ }^{75}$ As cells begin to form colonies, they enclose themselves in an EPS matrix. ${ }^{76,77}$ This 
matrix contains a diverse range of proteins, biopolymers, and exopolysaccharides that accumulate multivalent cations and macromolecules, which aids in keeping nutrients readily available for replicating cells and imposes sharp chemical gradients on the surroundings. ${ }^{3,78}$ They contain polar and apolar regions, and groups with hydrogen bonding potential, which allows them to sequester ions from the aqueous environment. ${ }^{3}$ During colony formation, bacteria can enhance chemical gradients by depleting nutrients from the local environment and producing a variety of charged metabolic wastes that accumulate in their place. ${ }^{73}$ In addition, bacteria require various ionic species, especially $\mathrm{K}^{+}, \mathrm{Ca}^{2+}$, and $\mathrm{Mg}^{2+}$ for proton transport and to neutralize or bridge polyanionic lipopolysaccharides on their outer membrane. ${ }^{79,80}$ As a consequence of these processes, there can be significant changes in the immediate extracellular conditions, including $\mathrm{pH}$, ionic strength, and osmolarity. It is also known that there is no contribution to the SFG signal that arises directly from the adherence of cells to the surface. ${ }^{17,18,81-83}$ One possibility is that the EPS binds directly to the silica surface, without any intervening water layer. We suspect that we are not probing water within the EPS, due to the need for solvating the high concentration of ions and other osmolytes in this matrix, leading to a disruption rather than enhancement of the polar alignment of water molecules. Therefore, we propose that when the bacteria are introduced into the SFG setup, cells accumulate at the silica surface, creating a microenvironment in the process, wherein water molecules and other hydrated ionic species attracted to the surface become trapped between the surface and the EPS matrix, resulting in a local $\mathrm{pH}$ and ionic strength that differs significantly from the bulk solution.

\section{Effect of the interfacial micro-environment on surface conditions}

At near-neutral $\mathrm{pH}$, where these experiments were performed, the effect of salt on the silica surface charge and dissolution rate is enhanced. ${ }^{26}$ This is due to the low buffering capacity of the surface groups, which leads to a large sensitivity of water molecules at the interface to the introduction of metal cations. Such heightened sensitivity could account for the increase in SFG signal intensity observed in the presence of growing E. coli in this interfacial micro-environment. If ions were removed from the surface through attraction to the EPS matrix, the ionic strength would be decreased within the interfacial micro-environment. This would cause an increase in ordering of water molecules trapped there and/or a reorientation of those waters, resulting in an increase in the SFG intensity. Moreover, waters in the hydration shell of alkali cations attracted to the negatively charged silica can dissociate, leading to an accumulation of hydroxide anions at the surface and thus an increase in the local $\mathrm{pH}$. The results from Darlington et al..$^{29}$ indicate that the $\mathrm{pH}$ of the microenvironment would have to increase to a $\mathrm{pH}$ between 8 and 9 in order to account for the $250 \%$ increase in SFG intensity. This was not observed in the bulk solution, which changed from approximately $\mathrm{pH} 6.5$ to 8 [Fig. 1(c)]. Such an increase is plausible, however, given that increasing concentrations of metabolic waste products like ammonium would migrate to the negatively charged silica and become trapped, enhancing local $\mathrm{pH}$ increases. This would result in an altered structure of interfacial water molecules that causes the SFG signal to increase. Any remaining trapped cations would also have this effect, increasing local $\mathrm{pH}$ through dissolution of their solvation waters, although this would be a small contribution. The combination of these processes could result in the required $\mathrm{pH}$ increase and ionic strength decrease since the diffusion rates of the bulk solution into the local surroundings are low. ${ }^{84}$

The increase in spectral intensity closely follows the growth curve and is consistent with the effect of the microenvironment on the interfacial $\mathrm{pH}$ and ionic strength. The concentration of ammonium is linked closely to their growth rate, as is the formation of the EPS matrix. During their lag and early exponential growth phases, E. coli have a predominately negative surface charge and so experience electrostatic repulsion with each other and negatively charged regions of silica. ${ }^{85}$ As a result, less interaction occurs with the surface, resulting in very few colonies forming. During this time, very little EPS matrix is produced. As growth progresses, polysaccharide concentrations on the outer membrane increase, displacing the previously uniform charge distribution. ${ }^{86}$ This results in less electrostatic repulsion and greater chances for colony formation. As the bacteria multiply, it becomes an exponential pattern as more cells are available for interaction with other cells and surfaces. Another effect of metabolism is in compositional changes to the immediate environment, resulting in reorientation of proteins near the surface and allowing for greater orientation of interfacial water molecules. ${ }^{87}$ As the cells reach the stationary phase, they are secreting metabolites at a fraction of the rate they were during exponential growth, since there are very few cells still dividing at this stage. ${ }^{86}$ This is reflected in the SFG spectra, which also plateau as a result of the relatively constant solution composition, $\mathrm{pH}$, and ionic strength in the micro-environment, as well as in the bulk medium.

All of the changes in $\mathrm{pH}$ and ionic strength that occur in the micro-environment happen as a result of cell growth. This explains why they are only observed in the online growth experiments. Despite the same metabolic processes occurring in each fraction taken from offline and online conditions and given that both experiments were sampled at the same time points, the increase in water SFG signal was only seen if cells were given prolonged access to the surface, as in the online experiments. This allows for colonies, and subsequently micro-environments, to form. In light of this, when fractions containing cells interact with the surface only during the brief period of measurement (5 min), the cells do not have sufficient time to establish a large increase in $\mathrm{pH}$ in the microenvironment as would be observed with cells actively growing there. Thus, only the small increase in bulk $\mathrm{pH}$ exists for these later fractions, which, as stated previously, is not enough to account for the increase in SFG intensity.

A small amount of signal increase did occur when the growth media devoid of cells was monitored spectroscopically in the sample cell over time, but only with a mature culture. As seen in Fig. 3, when media interacted with the silica surface over time, fractions from the late exponential phase (collected 
at $14 \mathrm{~h}$ ) displayed a $60 \%$ increase and those from the stationary phase (collected at $25 \mathrm{~h}$ ) displayed a $45 \%$ increase. These fractions are relatively exhausted in nutrients, but rich in metabolic products and cellular components from the growing culture. Therefore, it is likely that EPS fragments and other extracellular proteins may settle near the surface and still retain some of their chemical behavior, such as accumulation of ions and macromolecules through electrostatic and specific interactions. As net diffusion of ions away from the surface occurs as a time-dependent accumulation of extracellular components near the interface, it displays a trend that is similar to online cell growth, but reduced in scale. This is because the cells are not there to aid in the production of an extensive matrix of EPS and are not producing ammonium to increase the $\mathrm{pH}$ at the interface. Consequently, the ionic strength and $\mathrm{pH}$ differences in the micro-environment at the surface are much less when there are no cells present. This is evident in Fig. 3(a) which shows that the increase seen in the 14 and $25 \mathrm{~h}$ fractions is still only approximately $30 \%$ compared with the initial water signal, while online growth with cells present reaches $53 \%$ [Figs. 1(b) and 2].

\section{CONCLUSIONS}

We have observed that water is a sensitive reporter of interfacial conditions during bacterial growth. Although the silica-water surface structure in the presence of the initial growth medium is substantially altered from that of the neat surface as a result of the osmolytes and high ionic strength, this structure does not change as a function of time. However, when cellular excretion products enter the solution and adsorb on the surface, those molecules enhance the interfacial water signal, attributed to a reduction in the local ionic strength as extracellular polymeric substances deplete ions from the interface. When cells are present, the increasing $\mathrm{pH}$ of the immediate environment due to their metabolism causes a further increase in the surface water response. Further work is needed to determine the extent of solution composition changes during cell growth and the micro-environment composition. This may be accomplished with metabolomics assays of the filtered growth media for each snapshot along the growth curve, combined with ATR-IR or confocal Raman spectroscopy to probe the composition near the silica surface.

\section{ACKNOWLEDGMENTS}

This project was supported by a Discovery Grant from the Natural Science and Engineering Research Council of Canada (NSERC). The SFG spectrometer was purchased with assistance from the Canadian Foundation for Innovation Leader's Opportunity Fund and the British Columbia Knowledge Development Fund. We thank Sarah Kowallik, Adrianna Thompson, and Nat Jafarova for assistance with the cell surface adhesion characterization. Barb Currie and Rebecca Hof (UVic Biochemistry and Microbiology) provided valuable advice on the cell growth and preparation procedures. We thank Dr. Elizabeth Schneider at Biolin Scientific for use of the QCM-D instrument at the University of Victoria. Dr. Matthew Dixon at Biolin Scientific provided assistance with the QCM-D data analysis. T.A.J. is grateful to NSERC for a CGS-M scholarship. L.G. has received an NSERC USRA scholarship.

${ }^{1}$ D. G. Castner and B. D. Ratner, Surf. Sci. 500, 28 (2002).

${ }^{2}$ K. C. Dee, D. A. Puleo, and R. Bizios, in An Introduction to TissueBiomaterial Interactions (Wiley, 2002), Chap. 3, pp. 37-52.

${ }^{3}$ H.-C. Flemming and J. Wingender, Nat. Rev. 8, 623 (2010).

${ }^{4}$ A. H. L. Chamerlain, Biofilms Sci. Technol. 223, 59 (1992).

${ }^{5}$ D. Bakker, J. W. Klijnstra, K. J. Busscher, and H. C. van der Mei, Biofouling 19, 391 (2003).

${ }^{6}$ I. B. Beech, R. Gubner, V. Zinkevich, L. Hanjangsit, and R. Avci, Biofouling 16, 93 (2000).

${ }^{7}$ P. Stoodley, J. D. Boyle, D. deBeer, and H. M. Lappin-Scott, Biofouling 14, 75 (1999).

${ }^{8}$ M. Simões, L. C. Simões, and M. J. Vieira, LWT-Food Sci. Technol. 43, 573 (2010).

${ }^{9}$ I. W. Sutherland, Microbiology 147, 3 (2001).

${ }^{10}$ H. Ceri, M. E. Olson, C. Stremick, R. R. Read, D. Morck, and A. Buret, J. Clin. Microbiol. 37, 1771 (1999).

${ }^{11}$ M. Simoes, Curr. Med. Chem. 18, 2129 (2011).

${ }^{12}$ Y. Shen, J. Endod. 37, 657 (2011).

${ }^{13}$ P. N. Danese, L. A. Pratt, and R. Kolter, Methods Enzymol. 336, 19 (2001).

${ }^{14}$ K. E. Eboigbodin and C. A. Biggs, Biomacromolecules 9, 686 (2008).

${ }^{15}$ I. Eshet, V. Freger, R. Kasher, M. Herzberg, J. Lei, and M. Ulbricht, Biomacromolecules 12, 2681 (2011).

${ }^{16}$ L. D. Renner and D. B. Weibel, MRS Bull. 36, 347 (2011).

${ }^{17}$ E. Bulard, M.-P. Fontaine-Aupart, H. Dubost, W. Zheng, J.-M. Herry, M.-N. Bellon-Fontaine, R. Briandet, and B. Bourguignon, Spectrosc. Int. J. 27, 571 (2012).

${ }^{18}$ E. Bulard, Z. Guo, W. Zheng, H. Dubost, M.-P. Fontaine-Aupart, M.-N. Bellon-Fontaine, J.-M. Herry, R. Briandet, and B. Bourguignon, Langmuir 27, 4928 (2011).

${ }^{19}$ R. E. Baier, J. Biomech. Eng. 104, 257 (1982).

${ }^{20}$ N. Yee, J. B. Fein, and C. J. Daughney, Geochim. Cosmochim. Acta 64, 609 (2000).

${ }^{21}$ W. Norde and J. Lyklema, Colloids Surf. 38, 1 (1989).

${ }^{22}$ D. Nagasawa, T. Azuma, H. Noguchi, K. Uosaki, and M. Takai, J. Phys. Chem. C 119, 17193 (2015).

${ }^{23}$ V. Hlady, J. Buijs, and H. P. Jennissen, Methods Enzymol. 309, 402 (1999).

${ }^{24}$ L. Giussani, G. Tabacchi, E. Gianotti, S. Coluccia, and E. Fois, Philos. Trans. R. Soc., A 370, 1463 (2012).

${ }^{25}$ A. A. Hassanali and S. J. Singer, J. Phys. Chem. B 111, 11181 (2007).

${ }^{26}$ P. M. Dove, N. Han, A. F. Wallace, and J. J. De Yoreo, Am. J. Sci. 294, 665 (1994).

${ }^{27}$ M. Sovago, R. K. Campen, H. J. Bakker, and M. Bonn, Chem. Phys. Lett. 470, 7 (2009).

${ }^{28}$ E. L. DeWalt-Kerian, S. Kim, M. S. Azam, H. Zeng, Q. Liu, and J. M. Gibbs, J. Phys. Chem. Lett. 8, 2855 (2017).

${ }^{29}$ A. M. Darlington, T. A. Jarisz, E. L. DeWalt-Kerian, S. Roy, S. Kim, M. S. Azam, D. K. Hore, and J. M. Gibbs, J. Phys. Chem. C 121, 20229 (2017).

${ }^{30}$ S. Dewan, M. S. Yeganeh, and E. Borguet, J. Phys. Chem. Lett. 4, 1977 (2013).

${ }^{31}$ S. Dewan, V. Carnevale, A. Bankura, A. Eftekhari-Bafrooei, G. Fiorin, M. L. Klein, and E. Bourget, Langmuir 30, 8056 (2014).

${ }^{32}$ M. Dishon, O. Zohar, and U. Sivan, Langmuir 27, 12977 (2011).

${ }^{33}$ K. A. Lovering, A. K. Bertram, and K. C. Chou, J. Phys. Chem. C 120, 18099 (2016)

${ }^{34}$ B. M. Lowe, Y. Maekawa, Y. Shibuta, T. Sakata, C. K. Skylarist, and N. G. Green, Phys. Chem. Chem. Phys. 19, 2687 (2017).

${ }^{35}$ J. Schaefer, G. Gonella, M. Bonn, and E. H. G. Backus, Phys. Chem. Chem. Phys. 19, 16875 (2017).

${ }^{36}$ Z. Yang, Q. Li, and K. C. Chou, J. Phys. Chem. C 113, 8201 (2009).

${ }^{37}$ R. L. York, O. Mermut, D. C. Phillips, K. R. McCrea, R. S. Ward, and G. A. Somorjai, J. Phys. Chem. C 111, 8866 (2007).

${ }^{38}$ M. Fletcher and J. Gen, Microbiology 94, 400 (1976).

${ }^{39}$ D. Ørstavik, Acta Pathol. Microbiol. Scand., Sect. B: Microbiol. 85B, 38 (1977).

${ }^{40}$ M. Rosenberg and S. Kjelleberg, Adv. Microb. Ecol. 9, 353 (1986).

${ }^{41}$ A. Terlizzi, S. Fraschetti, P. Gianguzza, M. Faimali, and F. Boero, Aquat. Conserv.: Mar. Freshwater Ecosyst. 11, 311 (2001). 
${ }^{42}$ M. Simões, M. O. Pereira, and M. J. Vieira, Water Sci. Technol. 47, 217 (2003).

${ }^{43}$ L. E. Chávez de Paz, G. Bergenholtz, and G. Svensäter, J. Endod. 36, 70 (2010).

${ }^{44}$ T. A. Norton, R. C. Thompson, J. Pope, C. J. Veltkamp, B. Banks, C. V. Howard, and S. J. Hawkins, Aquat. Microb. Ecol. 16, 199 (1998).

${ }^{45}$ J. W. Costerton, The Biofilm Primer (Springer, Heidelberg, 2007).

${ }^{46}$ T. Romeo, Bacterial Biofilms (Springer, Heidelberg, 2008).

${ }^{47}$ H.-C. Flemming, Springer Ser. Biofilms 5, 81 (2011).

${ }^{48}$ M. Tanaka, T. Hayashi, and S. Morita, Polym. J. 45, 701 (2013).

${ }^{49}$ K. C. Jena and D. K. Hore, Phys. Chem. Chem. Phys. 12, 14383 (2010).

${ }^{50}$ Y. R. Shen, Pure Appl. Chem. 73, 1589 (2001).

${ }^{51}$ K. B. Eisenthal, Chem. Rev. 96, 1343 (1996).

${ }^{52}$ F. M. Geiger, Annu. Rev. Phys. Chem. 60, 61 (2009).

${ }^{53}$ M. J. Shultz, C. Schnitzer, D. Simonelli, and S. Baldelli, Int. Rev. Phys. Chem. 19, 123 (2000).

${ }^{54}$ K. C. Jena and D. K. Hore, J. Phys. Chem. C 113, 15364 (2009).

${ }^{55}$ M. C. Dixon, J. Biomol. Technol. 19, 151 (2008).

${ }^{56}$ M. V. Voinova, M. Rodahl, M. Jonson, and B. Kasemo, Phys. Scr. 59, 391 (1999).

${ }^{57}$ T. A. Jarisz, K. C. Jena, M. C. Dixon, and D. K. Hore, J. Phys. Chem. C 121, 16879 (2017).

${ }^{58}$ E. Jones, T. Oliphant, P. Peterson et al., SciPy: Open source scientific tools for Python, 2001.

${ }^{59}$ J. D. Hunter, Comput. Sci. Eng. 9, 90 (2007).

${ }^{60}$ G. Gonella, C. Lütgebaucks, A. G. F. de Beer, and S. Roke, J. Phys. Chem. C 120, 9165 (2016)

${ }^{61}$ P. E. Ohno, H. fei Wang, and F. M. Geiger, Nat. Commun. 8, 1032 (2017).

${ }^{62}$ J. F. D. Liljelad and E. Tyrode, J. Phys. Chem. C 116, 22893 (2012).

${ }^{63}$ G. Sposito, The Chemistry of Soils, 2nd ed. (Oxford University Press, London, 2008).

${ }^{64}$ G. M. Marion and K. L. Babcock, Soil Sci. 122, 181 (1976).

${ }^{65}$ Q. Du, E. Freysz, and Y. R. Shen, Phys. Rev. Lett. 72, 238 (1994).

${ }^{66}$ K. C. Jena, P. A. Covert, and D. K. Hore, J. Phys. Chem. Lett. 2, 1056 (2011).

${ }^{67}$ P. A. Covert, K. C. Jena, and D. K. Hore, J. Phys. Chem. Lett. 5, 143 (2014).
${ }^{68}$ D. J. Segelstein, “The complex refractive index of water," M.Sc. thesis, University of Missouri, Kansas City, 1981.

${ }^{69}$ M. R. Querry, R. C. Waring, W. E. Holland, G. M. Hale, and W. Nijm, J. Opt. Soc. Am. 62, 849 (1972).

${ }^{70}$ M. R. Querry, W. E. Holland, and R. C. Waring, J. Opt. Soc. Am. 66, 830 (1976).

${ }^{71}$ T. Tumolo, L. Angnes, and M. S. Baptista, Anal. Biochem. 333, 273 (2004).

${ }^{72}$ A. A. Fisk, Proc. Nat. Acad. Sci. U. S. A. 36, 518 (1950).

${ }^{73}$ G. Sezonov, D. Joseleau-Petit, and R. D'Ari, J. Bacteriol. 189, 8746 (2007).

${ }^{74}$ S. Baron, Medical Microbiology (University of Texas Medical Branch, Galveston, 1996)

${ }^{75}$ W. M. Dunne, Jr., Clin. Microbiol. Rev. 15, 155 (2002).

${ }^{76} \mathrm{~J}$. W. Costerton, Z. Lewandowski, D. E. Caldwell, D. R. Korber, and H. M. Lappin-Scott, Annu. Rev. Microbiol. 49, 711 (1995).

${ }^{77}$ D. H. Limoli, C. J. Jones, and D. J. Wozniak, Microbiol. Spectrom. 3, 1 (2015).

${ }^{78}$ R. M. Donlan, Emerging Infect. Dis. 8, 881 (2002).

${ }^{79}$ A. Polissi and P. Sperandeo, Mar. Drugs 12, 1023 (2014).

${ }^{80}$ L. A. Clifton, M. W. A. Skoda, A. P. Le Brun, F. Ciesielski, I. Kuzmenko, S. A. Holt, and J. H. Lakey, Langmuir 31, 404 (2015).

${ }^{81}$ C. Howell, M.-O. Diesner, M. Grunze, and P. Koelsch, Langmuir 24, 13819 (2008).

${ }^{82}$ M.-O. Diesner, C. Howell, V. Kurz, D. Verreault, and P. Koelsch, J. Phys. Chem. Lett. 1, 2339 (2010).

${ }^{83}$ E. Bulard, M.-P. Fontaine-Aupart, H. Dubost, W. Zheng, M.-N. Bellon-Fontaine, J.-M. Herry, and B. Bourguignon, Langmuir 28, 17001 (2012).

${ }^{84}$ J. R. Lawrence, G. M. Wolfaardt, and D. R. Korber, Appl. Environ. Microbiol. 60, 1166 (1994)

${ }^{85}$ P. Gilbert, D. J. Evans, E. Evans, I. G. Duguid, and M. R. W. Brown, J. Appl. Bacteriol. 71, 72 (1991).

${ }^{86}$ R. Kolter, D. A. Siegele, and A. Tormo, Annu. Rev. Microbiol. 47, 855 (1993).

${ }^{87}$ K. Meister, S. J. Roeters, A. Paananen, S. Woutersen, J. Versluis, G. R. Szilvay, and H. J. Bakker, J. Phys. Chem. Lett. 8, 1772 (2017). 